\title{
Participação social e democratização das mídias: caminhos para ampliar os direitos à comunicação e à saúde
}

Social participation and media democratization: ways to expand the rights to communication and health

Participación social y democratización de los medios de comunicación: formas de ampliar los derechos de comunicación y salud

Pâmela Pinto ${ }^{1, a}$

pinpamela@gmail.com | https://orcid.org/o000-0002-9699-7073

${ }^{1}$ Universidade de Aveiro, Departamento de Comunicação e Arte, DigiMedia Research Centre. Aveiro, Portugal.

a Doutorado em Comunicação pela Universidade Federal Fluminense. 


\section{RESUMO}

O livro Direito à Comunicação e Saúde discute a inter-relação entre esses dois direitos humanos e o seu reflexo no exercício da cidadania. Os autores traçaram uma retrospectiva das interfaces entre os dois campos, sobretudo a partir das mobilizações que originaram o Sistema Único de Saúde (SUS) e do cenário regulatório da radiodifusão e da Internet no país. A democratização da comunicação brasileira e a ampliação da participação social foram descritas como elementos centrais para configuração de uma sociedade democrática. A obra defende a comunicação como um bem público, que dever ser partilhado por todos.

Palavras-chave: Políticas de comunicação; Direito à comunicação; Direito à saúde; Participação social; Comunicação e saúde.

\section{ABSTRACT}

The book Right to Communication and Health discusses the interrelationship between these two human rights and their reflection on the exercise of citizenship. The authors look back on the connection between these two fields, especially from the mobilizations that originated the Brazilian Unified Health System (SUS) and the regulatory scenario (broadcasting and the Internet) in the country. The democratization of Brazilian communications and the expansion of social participation were described as central elements for the configuration of a democratic society. The work advocates for communication as a public good that should be collectively shared.

Keywords: Communication policy; Right to communication; Right to health; Social participation; Communication and health.

\section{RESUMEN}

El libro Derecho a la Comunicación y a la Salud analiza la interrelación entre estos dos derechos humanos y su reflejo en el ejercicio de la ciudadanía. Los autores trazan una retrospectiva de las interfaces entre los dos campos, especialmente a partir de las movilizaciones que originaron el Sistema Único de Salud (SUS) y el escenario regulatorio de la radiodifusión e Internet en el país. La democratización de la comunicación brasileña y la ampliación de la participación social fueron descritas como elementos centrales para la configuración de una sociedad democrática. La obra defiende la comunicación como un bien público que debe ser compartido por todos.

Palabras clave: Política de la comunicación; Derecho a la comunicación; Derecho a la salud; Participación social; Comunicación y salud.

Obra resenhada: STEVANIM, Luiz Felipe; MURTINHO, Rodrigo. Direito à comunicação e saúde. Rio de Janeiro: Editora Fiocruz, 2021. E-book. (Temas em saúde).

Contribuição dos autores: a autora é responsável por todo o texto.

Declaração de conflito de interesses: não há.

Fontes de financiamento: não houve.

Considerações éticas: não há.

Agradecimentos/Contribuições adicionais: não há.

Histórico do artigo: submetido: 10 set. 2021 | aceito: 10 set. 2021 | publicado: 10 nov. 2021.

Apresentação anterior: não há.

Licença CC BY-NC atribuição não comercial. Com essa licença é permitido acessar, baixar (download), copiar, imprimir, compartilhar, reutilizar e distribuir os artigos, desde que para uso não comercial e com a citação da fonte, conferindo os devidos créditos de autoria e menção à Reciis. Nesses casos, nenhuma permissão é necessária por parte dos autores ou dos editores. 
Em 2020, autoridades sanitárias de todo o mundo enfrentaram, simultaneamente, o novo coronavírus e uma infodemia - epidemia de desinformação sobre este vírus (EYSENBACH, 2020). No Brasil, a infodemia teve o governo federal como um dos seus atores centrais, sobretudo, por intermédio da sua principal autoridade sanitária, o Ministério da Saúde (MS). Contrariando as recomendações da Organização Mundial da Saúde, o MS promoveu o uso de medicamentos ineficazes contra a Covid-19 nos seus canais oficiais de comunicação com o cidadão (PINTO; ANTUNES; ALMEIDA, 2021; RECUERO et al., 2021). O órgão também reduziu a transparência na condução da pandemia por meio do apagão de dados acerca dos números de pessoas infectadas e de mortes (LOPES; LEAL, 2020). Assim, consórcios entre instituições de ensino, pesquisa e grupos midiáticos passaram a informar a sociedade sobre o avanço do vírus. O MS atravessou o primeiro ano da pandemia em uma gestão ineficiente e opaca da crise sanitária, principalmente no que se referiu à prestação de informações de interesse público - dentre elas, as orientações sobre prevenção. Tal cenário aconteceu em um momento no qual a saúde, a educação e instituições de pesquisa enfrentavam cortes orçamentários e frequentes ataques por parte de atores governamentais. O quadro descrito acima ocorreu 33 anos após a saúde se tornar um direito do cidadão e um dever do Estado brasileiro, inscrito na Constituição Federal de 1988 (CF88).

O livro Direito à Comunicação e Saúde foi publicado após 18 meses de convivência dos brasileiros com o novo coronavírus e contribuiu para estreitar o entendimento da correlação entre os direitos à comunicação e à saúde. A obra reforçou a pertinência dos elos entre essas áreas, traçados a partir da perspectiva dos direitos humanos. Tanto a saúde como a comunicação são tensionadas por interesses públicos e privados e têm impacto direto na realidade dos cidadãos. Não por acaso, ambas têm sido afetadas na presente crise sanitária e política por movimentos antidemocráticos, propagadores de discursos de ódio e desinformação (WARDLE; DERAKHSHAN, 2017). Tal conjuntura reforça as reflexões advindas deste livro, que enfoca em uma agenda pouco explorada e necessária à cena pandêmica: a interface entre os direitos à saúde e à comunicação. A obra integra a coleção Temas de Saúde, da Editora Fiocruz, e foi estruturada em cinco capítulos, além da introdução e das considerações finais. Ela contempla o caráter pedagógico dessa coleção, ao explicar a importância da comunicação na saúde (e vice-versa) aos atores dessas áreas.

Ancorado no olhar da Economia Política da Comunicação (EPC), o livro apresentou aspectos da configuração da mídia brasileira, suas tensões e lacunas em um ambiente democrático em permanente construção. O estudo expandiu a abordagem dialógica apontada pelas pesquisadoras Inesita Soares e Janine Cardoso (2007) no livro Comunicação e Saúde. Luiz Felipe Stevanim e Rodrigo Murtinho (2021) analisaram a interface entre as duas áreas na correlação entre as políticas de comunicação e saúde. Os autores enfatizam a participação social enquanto uma posição estratégica de resistência e um caminho para o protagonismo do cidadão na busca por direitos. Apesar do intervalo entre as duas obras, notou-se a vigência da tensão estabelecida na interação entre os dois campos, representadas em uma perspectiva instrumental da comunicação (comunicação em saúde) e na sua vertente dialógica (comunicação e saúde). O estudo é um ponto de convergência nas trajetórias acadêmicas e profissionais dos autores, uma vez que Stevanim e Murtinho trouxeram contribuições das suas agendas de pesquisas na EPC e do trabalho desenvolvido na Fundação Oswaldo Cruz (Fiocruz). É a partir das experiências articuladas nesses espaços que os autores desenvolvem os argumentos apresentados no livro.

No primeiro capítulo, 'Cidadania, Direitos e Democracia: pontes entre saúde e comunicação', realizou-se um recorte histórico para a tessitura entre as políticas de saúde e de comunicação, explicado à luz da teoria gramsciana. O Sistema Único de Saúde (SUS) foi usado como exemplo para construção dessas pontes, resultantes de disputas e negociações entre o Estado e sociedade civil em busca da formação de consensos durante a redemocratização do país. O SUS é apresentado como fruto de mobilizações sociais que conquistaram a saúde como um direito universal. Foi concebido a partir da descentralização, participa- 
ção social e do controle exercido pelos cidadãos, logo necessitou de um ambiente democrático para existir. A segunda ponte referiu-se ao potencial das políticas públicas de comunicação em promover a concretização e a ampliação das experiências de participação social, e a terceira assinalou a influência de atores privados nos dois campos. Para os autores, a promoção do direito à comunicação é um dos requisitos para se garantir o exercício da cidadania e a participação popular - princípios do SUS.

Os autores defendem o direito a comunicação como inalienável, capaz de unir a perspectiva individual à coletiva e de entender o processo de comunicação na relação dialética entre as dimensões humana e técnica. Ele abrangeria a liberdade de informação, a participação política, a vivência em sociedade e a garantia das condições de desenvolvimento dos indivíduos, na particularidade de suas experiências e de sua cultura. Em um esforço para tornar tangível a compreensão do tema, em uma sociedade hiperconectada e composta por diferentes grupos sociais, os autores reuniram propostas discutidas desde 1980 no capítulo 'Direito Humano à Comunicação: origens, sentidos e disputas'. A democratização da comunicação foi apontada como uma forma de mediar este direito na sociedade, pois teria a capacidade de reestruturá-la, reduzindo desigualdades e ampliando o acesso e a participação na comunicação. Isso atribui um papel ativo ao cidadão, com capacidade de potencializar a variedade de mensagens e impactar a representação social. A viabilidade dessas propostas está relacionada a disputas no seio do capitalismo à brasileira, e é amparada por legislações como os artigos 54 e 223, da CF88. O primeiro proíbe o controle de concessões por políticos, e o segundo determina complementaridade entre os sistemas privado, público e estatal de mídia.

A década de 1980 é apontada como ponto de partida para a conexão entre a comunicação e a saúde no Brasil. Esta foi alavancada pela interação entre movimentos sociais dos dois segmentos, pelo reconhecimento da necessidade de políticas intersectoriais entre as áreas, pelo desenvolvimento do campo científico da comunicação e saúde, pela ampliação de projetos no âmbito do SUS e o entendimento da comunicação como área finalística em instituições de saúde. A construção das interfaces entre as áreas (ARAUJO; CARDOSO, 2007) foi remontada historicamente no terceiro capítulo, 'Vozes do SUS: participação social, comunicação e saúde'. Os pesquisadores propõem o direito à comunicação como estruturante aos demais direitos, entre eles, o da saúde. Reiteram a participação social como chave de mudanças no panorama atual, pois ela pode alavancar modificações em um sistema constituído por conglomerados (de radiodifusão e digitais) ao propor aos cidadãos uma perspectiva ativa no direito de comunicar. Nesta etapa do livro, desenvolve-se um argumento central à sua estrutura, o de que não há direito que seja perpétuo, mas sim uma construção constante da democracia, embasada em lutas sociais dinâmicas. Esta mensagem é oportuna no momento no qual se assiste ao avanço de perspectivas antidemocráticas e ao desmonte de conquistas sociais estabelecidas na CF88.

O quarto capítulo, 'Radiodifusão e Saúde: conflitos entre o público e privado', expôs os reflexos do domínio do interesse comercial em detrimento do público no engessamento de perspectivas de usos democráticos das mídias. Retomou a configuração do cenário regulatório da radiodifusão, marcado pelo controle privado de veículos massivos, sob a tutela do Estado, e a liderança de um conglomerado, o grupo Globo (LIMA, 2011). Tal estrutura tem influenciado a formulação de políticas públicas na comunicação (e na saúde) há mais de cinco décadas, com interferências nas elaborações de leis. Os autores alertam para a necessidade de outros modelos de mídia capazes de abarcar e promover a diversidade e os direitos. Stevanim e Murtinho (2021) reiteram a urgência de fortalecer a comunicação pública, vinculada à sociedade e gerida por colegiados plurais. Esse segmento tem sido desmontado sistematicamente, a partir do golpe que culminou com o impeachment de Dilma Rousseff em 2016. As experiências da Revista Radis e do Canal Saúde, elaborados a partir da Fiocruz, foram apresentadas como exemplos de contrapontos feitos na saúde, com capacidade de abrir espaço ao debate das políticas sanitárias e da inclusão de grupos marginalizados. 
O debate sobre a democratização das mídias avançou para o tempo presente, no qual foi problematizada a contradição entre liberdade e controle inscrita nas relações estabelecidas a partir da Internet. Neste ambiente reticular, cuja gestão é opaca e conduzida por conglomerados internacionais pautados na vigilância de dados, os cidadãos ficam vulneráveis aos interesses mercadológicos (BOYD, 2015). No capítulo cinco, 'Direitos Digitais e Saúde: entre dilemas e possibilidades', enfocou-se o acesso à Internet como um direito humano e problematizaram-se as tensões decorrentes desta vulnerabilidade. Os autores alertam para o uso político dos dados, o consequente impacto na democracia e para táticas de vigilância, em detrimento dos direitos humanos. As assimetrias alavancadas por estas plataformas também foram questionadas, uma vez que elas têm mostrado parcialidade junto às atividades antidemocráticas na rede, especialmente com a propagação da desinformação nas redes sociais digitais e no uso de dados por meio da lógica algorítmica. A exclusão digital foi enfocada como um fator de aprofundamento das desigualdades e como um obstáculo para o exercício de direitos. Foram apresentadas ações vigentes de governança digital no país, com demandas de universalização do acesso, proteção da privacidade e dados, e garantia da liberdade de expressão, especialmente a partir dos debates em curso para novas legislações sobre desinformação e segurança dos dados pessoais.

Depois de justificar a coexistência entre os direitos à comunicação e à saúde nos capítulos anteriores, Stevanim e Murtinho (2021) propuseram um diálogo permanente entre os dois segmentos - alicerçado nas questões do presente, mas atentos às raízes históricas, limites e contradições dos seus atores e contextos. Nas conclusões, 'Encruzilhadas: desafios do presente para refletir o futuro', recomendaram o fortalecimento de lutas democráticas frente ao desmonte da CF88 com atenção às lacunas deixadas desde a redemocratização. As tensões vigentes no ambiente digital, no qual coexistem experiências comunitárias e a disseminação de desinformação, são questões do momento atual; o enfrentamento das desigualdades no exercício do direito à comunicação, afetando assim a garantia da saúde universal e integral aos cidadãos; e, por fim, os autores reiteraram a necessidade de interlocução entre diferentes atores da sociedade civil e as instituições na construção da comunicação. O livro encerrou com uma mensagem constante em todos os capítulos: "comunicação é um bem público que dever ser partilhado por toda a sociedade". Ao final foram oferecidas sugestões de leituras que dialogam com a EPC e fontes sobre o direito à comunicação e à saúde.

O livro ajudou a consolidar as pontes existentes entre os estudos de comunicação e saúde ao detalhar as intersecções entre os movimentos sociais em torno da cidadania, pautados por direitos humanos, e ao sintetizar tensões do cenário midiático e sua (des)regulação. O texto sinalizou agendas de interesse social a serem observadas como os elos entre regulação midiática, consumo e saúde, a pauta acerca dos direitos humanos, diversidade e mídia, além de tópicos sobre desinformação e saúde. Estes pontos podem ampliar o debate acerca da conexão entre essas áreas e apresentar propostas para o estreitamento desse vínculo. O trabalho cartografou um conjunto de atores e suas demandas para a democratização das mídias, porém observou-se uma ênfase nas contribuições realizadas a partir da Fiocruz.

Trabalhos futuros podem colaborar para expandir a visibilidade de outras iniciativas que correlacionaram a saúde pública e comunicação no território brasileiro. Outro tema complementar a este estudo diz respeito à inserção do pleito pelos direitos à comunicação e à saúde na Agenda 2030 para o Desenvolvimento Sustentável da ONU. O documento elaborado em 2015 é um guia composto por 17 Objetivos de Desenvolvimento Sustentável (ODS) que se desdobram em 169 metas e 230 indicadores globais a serem trabalhados pelos países-membros até 2030. A aproximação dos ODS 3 (Saúde de Qualidade) e ODS 16 (Paz, Justiça e Instituições eficazes) no seu item 16.10 "acesso público à informação e às liberdades fundamentais" (ONU, 2015), é apontada pela Unesco como uma abordagem para o fortalecimento da saúde e de enfrentamento à desinformação nessa área (BONTCHEVA; POSETTI, 2020). 
Ao evidenciar a participação popular como uma condição fundamental na promoção do diálogo entre os direitos à comunicação e à saúde, o livro desafia as duas áreas a educar os brasileiros para a existência de modelos alternativos de comunicação, geridos a partir da perspectiva cidadã. Isso implica em expor o direito de fala, da participação em instâncias deliberativas da programação, de controle social dos conteúdos, de conscientizar sobre o direito à privacidade e à proteção de dados no ambiente digital. Desde a ditadura militar (1964-1985), a experiência midiática no Brasil foi centrada nas redes de TV com abrangência nacional, geridas por atores privados, com limitado debate social sobre alternativas a esse quadro. $\mathrm{O}$ avanço progressivo da Internet, marcado por profundas desigualdades de acesso no território, tem afetado o domínio desse modelo, contudo também carrega tensões entre os interesses públicos e privados. Para Coutinho (2004), a defesa do controle das mídias pela sociedade, em detrimento dos grupos monopolistas privados, passa a ser factível no bojo de processos de democratização geral da sociedade e pode ser mobilizada por meio do controle social junto aos meios de comunicação, designados no plano legislativo. Todavia, a atual conjuntura democrática não sinaliza para uma mudança da configuração midiática a curto prazo. Diante disso, o trabalho de Stevanim e Murtinho (2021) tem o potencial de estimular futuras pesquisas a problematizarem como ampliar a visibilidade das agendas de coletivos pela democratização das mídias, dos movimentos sociais no âmbito sanitário, das pesquisas acadêmicas, e de outras entidades que já atuam nessa mobilização há três décadas. A ideia de mobilização social, inscrita em disputas hegemônicas entre diferentes segmentos da sociedade civil, parece dar pistas a esse desafio.

\section{REFERÊNCIAS}

ARAÚJO, Inesita Soares de; CARDOSO, Janine Miranda. Comunicação e saúde. Rio de Janeiro: Editora Fiocruz, 2007.

BONRCHEVA, Kalina; POSETTI, Julie (Ed.) Balancing Act: countering digital disinformation while respecting freedom of expression. Genebra: International Telecommunication Union, 2020. Disponível em: https://www. broadbandcommission.org/wp-content/uploads/2021/02/WGFoEDisinfo_Report2020.pdf. Acesso em: 28 ago. 2021.

BOYD, Danah. Social media: a phenomenon to be analyzed. Social Media and Society, [s. I.], v. 1, n. 1, p. 1-2, 2015. DOI: https://doi.org/10.1177\%2F2056305115580148. Disponível em: https://journals.sagepub.com/ doi/full/10.1177/2056305115580148. Acesso em: 13 jan. 2021.

COUTINHO, Carlos Nelson. Intelectuais, luta política e hegemonia cultural. In: MORAES, Dênis de (Org.). Combates e utopias: os intelectuais num mundo em crise. Rio de Janeiro: Record, 2004. p. 315-337.

EYSENBACH, Gunther. How to fight an infodemic: the four pillars of infodemic management. Journal of Medical Internet Research, Toronto, v. 22, n. 6, p. 21820, 2020. DOI: https://doi.org/10.2196/21820. Disponível em: https://www.jmir.org/2020/6/e21820. Acesso em: 12 dez. 2020.

LIMA, Venício Arthur de. Regulação das comunicações: história, poder e direitos. São Paulo: Paulus, 2011.

LOPES, Ivonete da Silva; LEAL, Daniela de Ulysséa. Entre a pandemia e o negacionismo: a comunicação de riscos da Covid-19 pelo governo brasileiro. Chasqui: Revista Latinoamericana de comunicación, Quito, v. 1, n. 145, p. 261-280, 2020. DOI: https://doi.org/10.16921/chasqui.v1i145.4350. Disponível em: https:// revistachasqui.org/index.php/chasqui/article/view/4350. Acesso em: 15 fev. 2021.

ORGANIZAÇÃO DAS NAÇÕES UNIDAS (ONU). Transforming our world: the 2030 Agenda for Sustainable Development. Genebra: A Organização, 2015. Disponível em: https://sdgs.un.org/2030agenda. Acesso em: 28 ago. 2021.

PINTO, Pâmela; ANTUNES, Maria João; ALMEIDA, Ana Margarida Pisco. Instagram como herramienta de salud pública: un estudio sobre América del Sur. Ámbitos Revista Internacional de Comunicación, Sevilha, v. 53, n. 2, p. 63-81, 2021. DOI: https://doi.org/10.12795/Ambitos.2021.i53. Disponível em: https:// revistascientificas.us.es/index.php/Ambitos/article/view/15857. Acesso em: 18 ago. 2021. 
Reciis - Revista Eletrônica de Comunicação, Informação \& Inovação em Saúde, Rio de Janeiro, v. 15, n. 4, p. 1084-1090, out./dez. 2021 [www.reciis.icict.fiocruz.br] e-ISSN 1981-6278

RECUERO, Raquel et al. Desinformação, mídia social e Covid-19 no Brasil: relatório, resultados e estratégias de combate. Pelotas: MIDIARS - Grupo de Pesquisa em Mídia Discurso e Análise de Redes Sociais, 2021. Disponível em: https://wp.ufpel.edu.br/midiars/files/2021/05/Desinformac\%CC\%A7a\%CC\%83ocovid-midiars-2021-1.pdf. Acesso em: 15 ago. 2021.

WARDLE, Claire; DERAKHSHAN, Hossein. Information disorder: toward an interdisciplinary framework for research and policy making. Estrasburgo: Council of Europe, 2017. Disponível em: https://rm.coe.int/ information-disorder-toward-an-interdisciplinary-framework-for-researc/168076277c. Acesso em: 28 ago. 2021. 